\title{
Aryl Cyanates. Reaction of Aryl Cyanates with Grignard Reagents. Kinetic Studies
}

\author{
ERIK HUGE-JENSEN and ARNE HOLM
}

Chemical Laboratory II (General and Organic Chemistry), The H. C. Ørsted Institute, University of Copenhagen, Universitetsparken 5, DK-2100 Copenhagen, Denmark

A kinetic investigation of the reactions of aryl cyanates with Grignard reagents and dibutylmagnesium in diethyl ether has been carried out. The reaction is best described as involving a concerted four-center mechanism in the ratedetermining step, first order both in aryl cyanate and in the organomagnesium species: alkyl- or arylmagnesium halide and dialkylor diarylmagnesium, present in the Grignard reagents.*

For reactions of $m$-substituted phenyl cyanates with "butylmagnesium bromide" a linear correlation is obtained between the logarithm of the rate constants and the Hammett sigma values with a $\varrho$-value of +0.97 . For reactions of $p$-substituted phenyl cyanates with "butylmagnesium bromide" it has not been possible to obtain a smooth curve when plotting the logarithm of the rate constants versus the Hammett sigma values.

The reaction constant for the reaction of phenyl cyanate with $p$-substituted "phenylmagnesium bromides" is calculated to be ca. -0.80 .

"Arylmagnesium bromides" are found to be more reactive than dibutylmagnesium, which again is more reactive than "butylmagnesium bromide".

In another paper ${ }^{1}$ we have described the product formation in the reaction between alkyl or aryl cyanates and Grignard reagents, and we now wish to report a kinetic investigation of the reaction between aryl cyanates and Grignard reagents.

The present work has been carried out in order to obtain information about the mechanism of the reaction (I) between aryl cyanates

* The Grignard reagents are in the following symbolized as "RMgX". and Grignard reagents, which leads to the formation of aryloxymagnesium halides and nitriles:

$$
\mathrm{ArOCN}+\mathrm{RMgX} \longrightarrow \operatorname{ArOMgX}+\mathrm{RCN}
$$

A thermographic method $2 \mathrm{a}, \mathrm{b}$ was used for the kinetic measurements, and this technique allowed rate measurements reproducible within $\pm 5 \%$ by use of a concentration of $0.01 \mathrm{M}$ of the reagent present in lesser amount. All measurements were carried out with one of the reagents in excess.

Fig. 1 shows three examples of plots of $\ln \left(\Delta T_{\infty}-\Delta T_{1}\right) /\left(\Delta T_{\infty}-\Delta T\right) *$ versus the reaction time, $t$, for the reaction of phenyl cyanate with "butylmagnesium bromide". From all kinetic measurements linear plots were obtained for at least $70 \%$ transformation of the limiting reagent. The linearity of the plots means that the reaction order in phenyl cyanate is one. The pseudo first order rate constants $\left(k_{\text {obs }}\right)$ are obtained from the slopes of the lines and found to be linearly dependent on the initial concentration of Grignard reagent (Fig. 2), and therefore the reaction order in "butylmagnesium bromide" is assumed to be one. Because of the association of most Grignard reagents at concentrations above $0.1 \mathrm{M}^{3}$ it is surprising that

${ }^{*} \operatorname{Ln} a /(a-x)=\ln \left(\Delta T_{\infty}-\Delta T_{1}\right) /\left(\Delta T_{\infty}-\Delta T\right)=k_{\mathrm{obs}} \times$ $t$, where $\Delta T_{\infty}$ is the total rise in temperature, $\Delta T_{1}$ is the rise in temperature after $2 \mathrm{~ms}$ and $\Delta T$ is the rise in temperature at the time $t . \Delta T_{1}$ is a correction for heat evolved from reaction between traces of impurities (water) and the Grignard reagent and from mixing.

Acta Chem. Scand. B 28 (1974) No. 7 


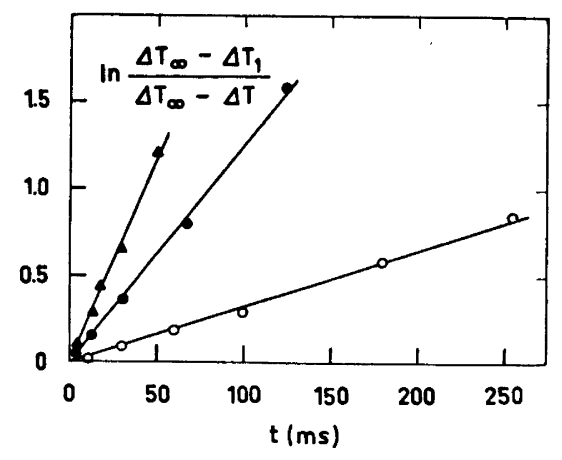

Fig. 1. Plot of $\ln \left(\Delta T_{\infty}-\Delta T_{1}\right) /\left(\Delta T_{\infty}-\Delta T\right)$ versus the reaction time, $t$, for the reaction of phenyl cyanate with excess "butylmagnesium bromide" in diethyl ether at $25^{\circ} \mathrm{C}\left(c^{0} \mathrm{C}_{6} \mathrm{H}_{5} \mathrm{OCN}=\right.$ $0.010 \mathrm{M}$; $c^{0}$ " $\mathrm{C}_{4 \mathrm{H}} \mathrm{MgBr}=0.103 \mathrm{M}(\mathrm{O}), 0.413 \mathrm{M}$ (O) and $0.750 \mathrm{M}(\Delta))$.

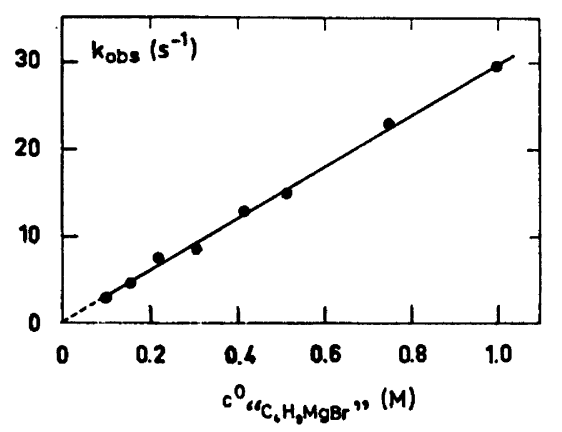

Fig. 2. Plot of the pseudo first order rate constant $\left(k_{\text {obs }}\right)$ versus the initial concentration of the Grignard reagent for the reaction of phenyl cyanate with excess "butylmagnesium bromide" in diethyl ether at $25^{\circ} \mathrm{C}\left(c^{0} \mathrm{CoH}_{\mathrm{oOCN}}=\right.$ $0.010 \mathrm{M}$ ).

the pseudo first order rate constant is linearly dependent on the initial concentration of "butylmagnesium bromide". However, the degree of association of "butylmagnesium bromide" has not been measured. This reagent could be associated to a lesser extent than the lower homologues because the degree of association decreases as the hydrocarbon chain is lengthened..$^{3}$ Another possibility is of course that the cyanate also reacts with the dimers (polymers) besides the organomagnesium species (butylmagnesium bromide and dibutylmagne. sium) involved in the Schlenk equilibrium (reac. tion (II)). ${ }^{4}$

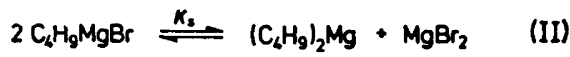

In kinetic measurements with a constant excess of "butylmagnesium bromide" the pseudo first order rate constant was found to be increased by $9 \%$ when the initial concentration of phenyl cyanate was doubled (Table 1). An increase is expected due to the tem.

Table 1. Pseudo first order rate constants for the reaction of phenyl cyanate with a constant excess of "butylmagnesium bromide" in diethyl ether at $25^{\circ} \mathrm{C}$.

\begin{tabular}{|c|c|c|}
\hline$c^{0}{ }_{\mathrm{C} \cdot \mathrm{H}_{6} \mathrm{OCN}}(\mathrm{M})$ & $c^{0}$ “"C.H॰MgBt" $(\mathrm{M})^{a}$ & $k_{\mathrm{obs}}\left(\mathrm{s}^{-1}\right)$ \\
\hline $\begin{array}{l}0.010 \\
0.020\end{array}$ & $\begin{array}{l}0.220 \\
0.220\end{array}$ & $\begin{array}{l}7.6 \\
8.3\end{array}$ \\
\hline
\end{tabular}

a Sublimed magnesium ("Specpure", Johnson, Matthey Chemicals Ltd.) was used for preparation of the "butylmagnesium bromide" used in these experiments.

perature dependence of the rate constant. The doubling of the concentration of phenyl cyanate doubles the total rise in temperature. On this

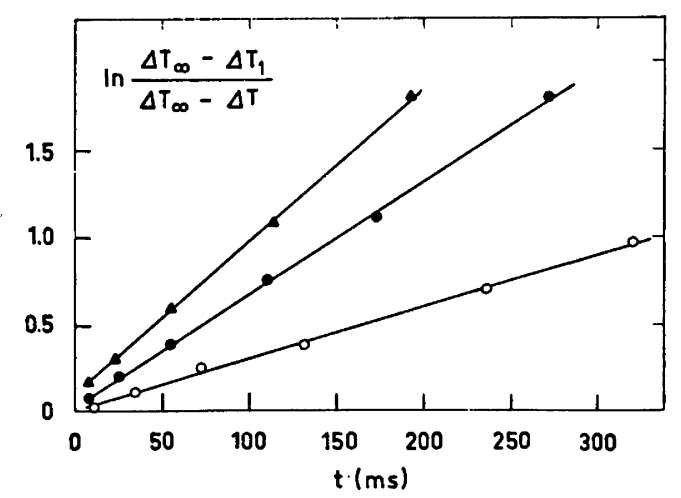

Fig. 3. Plot of $\ln \left(\Delta T_{\infty}-\Delta T_{1}\right) /\left(\Delta T_{\infty}-\Delta T\right)$ versus the reaction time, $t$, for the reaction of excess phenyl cyanate with "butylmagnesium bromide" in diethyl ether at $25{ }^{\circ} \mathrm{C}$ $\left(c^{0}\right.$ " $\mathrm{C}_{4 \mathrm{H}}, \mathrm{MgBr}=0.010 \mathrm{M} ; \quad c^{0}{ }_{\mathrm{C}_{\mathrm{H}} \mathrm{H}_{s} \mathrm{OCN}}=0.100 \mathrm{M}$ (O), 0.200 M (O) and $0.300 \mathrm{M}(\Delta))$.

Acta Chem. Scand. B 28 (1974) No. 7 
basis it is difficult to say anything about catalysis by traces of transition metals present in the magnesium used for the preparation of the Grignard reagent.

Kinetic measurements with excess phenyl cyanate and $0.010 \mathrm{M}$ "butylmagnesium bromide" likewise give linear pseudo first order plots (Fig. 3), and the pseudo first order rate constants obtained from the slopes of the curves are again linearly dependent on the initial concentration of the reagent in excess (phenyl cyanate). The $k_{\text {obs-values found with excess }}$ phenyl cyanate are almost equal to the $k_{\text {obs }}$ values found in measurements with excess "butylmagnesium bromide" (Table 2).

Table 2. Pseudo first order rate constants for the reaction of phenyl cyanate with "butylmagnesium bromide" in diethyl ether at $25^{\circ} \mathrm{C}$.

\begin{tabular}{lll}
\hline$c^{0}{ }_{\mathrm{C} \text { Hs } \mathrm{OCN}}(\mathrm{M})$ & $c^{0}{ }^{0}$ "C.HoMgBr" $(\mathrm{M})$ & $k_{\mathrm{obs}}\left(\mathrm{s}^{-1}\right)$ \\
\hline 0.010 & 0.100 & \\
0.100 & 0.010 & 2.9 \\
0.010 & 0.200 & 2.9 \\
0.200 & 0.010 & 6.2 \\
0.010 & 0.300 & 9.2 \\
0.300 & 0.010 & 8.6 \\
\hline
\end{tabular}

Because of the results reported above the rate of the reaction between phenyl cyanate and "butylmagnesium bromide" can be described by eqn. (1):

$-\mathrm{d}\left[\mathrm{C}_{6} \mathrm{H}_{5} \mathrm{OCN}\right] / \mathrm{d} t=k\left[\mathrm{C}_{6} \mathrm{H}_{5} \mathrm{OCN}\right]\left[{ }^{\circ \mathrm{C}_{4}} \mathrm{H}_{9} \mathrm{MgBr}\right.$ ']

We have made kinetic measurements on the reaction of phenyl cyanate with excess dibutylmagnesium and found that the $k_{\mathrm{obs}}$-value is a factor of 22 higher than the $k_{\mathrm{obs}}$-value for the reaction between phenyl cyanate and "butylmagnesium bromide" (Tables 2 and 3). The pseudo first order plots are linear for up to $80 \%$ transformation of phenyl cyanate (Fig. 4), and the pseudo first order rate constants are linearly dependent on the initial concentration of dibutylmagnesium (Table 3).

If only the dibutylmagnesium present in "butylmagnesium bromide" reacts with phenyl cyanate the $k_{\mathrm{obs}}$-value for the reaction of 0.010 $\mathrm{M}$ phenyl cyanate with $0.100 \mathrm{M}$ "butylmagne.
Table 3. Pseudo first order rate constants for the reaction of phenyl cyanate with excess dibutylmagnesium in diethyl ether at $25^{\circ} \mathrm{C}$.

\begin{tabular}{llc}
\hline$c^{0}{ }_{\mathrm{CH}_{b} \mathrm{OCN}}(\mathrm{M})$ & $c^{0}{ }_{\left(\mathrm{C}_{4} \mathrm{H}_{0}\right)_{2} \mathrm{Mg}}(\mathrm{M})$ & $k_{\mathrm{obs}}\left(\mathrm{s}^{-1}\right)$ \\
\hline 0.010 & 0.097 & 63 \\
0.010 & 0.194 & 134 \\
\hline
\end{tabular}

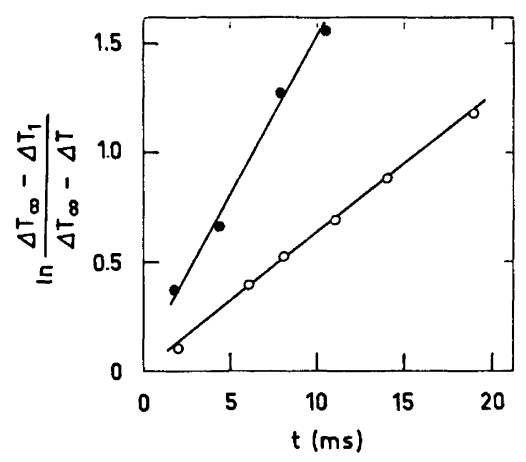

Fig. 4. Plot of $\ln \left(\Delta T_{\infty}-\Delta T_{1}\right) /\left(\Delta T_{\infty}-\Delta T\right)$ versus the reaction time, $t$, for the reaction of phenyl cyanate with excess dibutylmagnesium in diethyl ether at $25^{\circ} \mathrm{C}\left(c^{0} \mathrm{C}_{6} \mathrm{H}_{5} \mathrm{OCN}=0.010 \mathrm{M}\right.$; $c^{0}{ }_{\left(\mathrm{C}_{4} \mathrm{H}_{0}\right)_{2} \mathrm{Mg}}=0.097 \mathrm{M}(\mathrm{O})$ and $\left.0.194 \mathrm{M}(\bullet)\right)$.

sium bromide" can be calculated to be 2.1 $\mathrm{s}^{-1}, *$ which is $0.8 \mathrm{~s}^{-1}$ smaller than the observed value (Table 2). Therefore it seems reasonable to assume that both butylmagnesium bromide and dibutylmagnesium react when "butylmagnesium bromide" is reacting with phenyl cyanate.

When magnesium bromide etherate is added to "butylmagnesium bromide" the $k_{\text {obs }}$-value becomes smaller (Table 4). The concentration of dibutylmagnesium decreases according to the Schlenk equilibrium when magnesium bromide is added, and therefore it is reasonable that the pseudo first order rate constant becomes smaller. However, the value is still high, which we suppose is due to the reactivity of butylmagnesium bromide.

* The concentration of dibutylmagnesium in 0.100 $M$ "butylmagnesium bromide" is ca. $0.0032 \mathrm{M}$ for $K_{\mathrm{s}}=1 \times 10^{-3}$ (Ref. 5). The calculation of $k_{\mathrm{obs}}$ is made with the assumption that $k_{\mathrm{obs}}$ is linearly dependent on the initial concentration of dibutylmagnesium in the interval $0-0.1 \mathrm{M}$, thus $k_{\mathrm{obs}}=$ $63 \times 0.0032 / 0.097=2.1 \mathrm{~s}^{-1}$.

Acta Chem. Scand. B 28 (1974) No. 7 
Table 4. Pseudo first order rate constants for the reaction of phenyl cyanate with excess "butylmagnesium bromide" in diethyl ether at $25^{\circ} \mathrm{C}$.

\begin{tabular}{|c|c|c|c|}
\hline$c^{0} \mathrm{C}_{6} \mathrm{H}_{6} \mathrm{OCN}(\mathrm{M})$ & $c^{0}$ “c价MgBr" $(\mathrm{M})$ & $c^{0}{ }_{\mathrm{MgBr}}(\mathrm{M})$ & $k_{\text {obs }}\left(\mathrm{s}^{-1}\right)$ \\
\hline $\begin{array}{l}0.010 \\
0.010\end{array}$ & $\begin{array}{l}0.138 \\
0.138\end{array}$ & $\begin{array}{l}0.003 \\
0.069\end{array}$ & $\begin{array}{l}5.7 \\
4.4\end{array}$ \\
\hline
\end{tabular}

On basis of the results described above the rate expression (eqn. (1)) should consequently be:

$$
\begin{aligned}
& -\mathrm{d}\left[\mathrm{C}_{6} \mathrm{H}_{5} \mathrm{OCN}\right] / \mathrm{d} t=\left(k_{2}\left[\mathrm{C}_{4} \mathrm{H}_{8} \mathrm{MgBr}\right]+\right. \\
& \left.k_{2}{ }_{2}\left[\left(\mathrm{C}_{4} \mathrm{H}_{8}\right)_{2} \mathrm{Mg}\right]\right)\left[\mathrm{C}_{6} \mathrm{H}_{5} \mathrm{OCN}\right]
\end{aligned}
$$

where $k_{2}$ and $k_{2}^{\prime}$ are the second order rate constants for the reaction of phenyl cyanate with butylmagnesium bromide and dibutylmagnesium, respectively. $k_{2}{ }^{\prime}$ is calculated from the pseudo first order rate constant and the corresponding concentration of dibutyl-

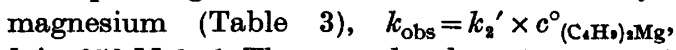
$k_{2}{ }^{\prime}=650 \mathrm{M}^{-1} \mathrm{~s}^{-1}$. The second order rate constant $\left(k_{2}\right)$ for the reaction of phenyl cyanate with butylmagnesium bromide can be calculated from the following equation:

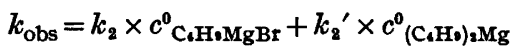

For $c^{0}$ "c $\mathrm{C}_{\mathrm{H}} \mathrm{H}_{\circ \mathrm{MgBr}}$ " $=0.100 \mathrm{M}, c^{0} \mathrm{C}_{\mathrm{d}} \mathrm{H}_{\circ \mathrm{MgBr}}=0.0936$ $\mathrm{M}, \quad c^{0}{ }_{\left(\mathrm{C}_{4} \mathrm{H}_{\mathrm{o}}\right)_{2} \mathrm{Mg}}=0.0032 \mathrm{M}$, and $k_{\mathrm{obs}}=2.9 \mathrm{~s}^{-1}$, which gives $k_{2}=8.6 \mathrm{M}^{-1} \mathrm{~s}^{-1}$.

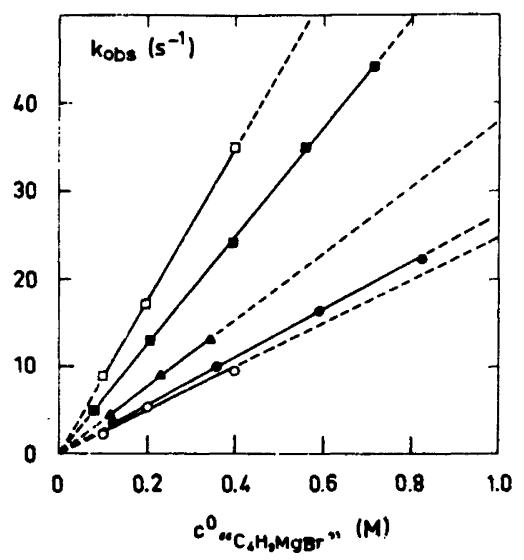

Fig. 5. Plot of pseudo first order rate constants versus the initial concentrations of the Grignard reagent for the reactions of $m$-substituted phenyl cyanates with excess "butylmagnesium bromide" in diethyl ether at $25{ }^{\circ} \mathrm{C}$ $\left(c^{0}{ }_{m-\mathrm{XC}} \mathrm{H}_{4} \mathrm{OCN}=0.010 \mathrm{M} ; m-\left(\mathrm{CH}_{3}\right)_{2} \mathrm{NC}_{6} \mathrm{H}_{4} \mathrm{OCN}\right.$ (O); $m-\mathrm{CH}_{3} \mathrm{C}_{6} \mathrm{H}_{4} \mathrm{OCN}(\mathrm{O}) ; m-\mathrm{CH}_{3} \mathrm{OC}_{6} \mathrm{H}_{4} \mathrm{OCN}$ $\left.(\Delta) ; m-\mathrm{ClC}_{6} \mathrm{H}_{4} \mathrm{OCN}(\square) ; m-\mathrm{CF}_{3} \mathrm{C}_{6} \mathrm{H}_{4} \mathrm{OCN}(\square)\right)$.

Table 5. Pseudo first order rate constants for the reaction of substituted phenyl cyanates with

\begin{tabular}{|c|c|c|c|}
\hline $\mathrm{X}-\mathrm{C}_{6} \mathrm{H}_{4} \mathrm{OCN}$ & $k_{\mathrm{obs}}\left(\mathrm{s}^{-1}\right)$ & $\log k / k_{0}$ & $\sigma^{0} a$ \\
\hline 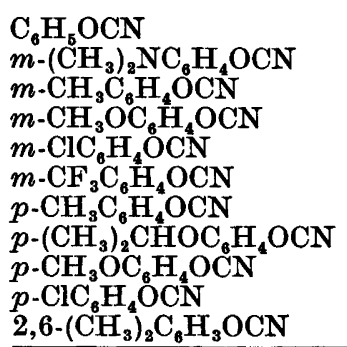 & $\begin{array}{l}2.9 \\
2.5 \\
2.8 \\
3.8 \\
6.2 \\
8.7 \\
3.0 \\
3.8 \\
4.8 \\
7.5 \\
9.1\end{array}$ & $\begin{array}{l}0 \\
-0.07 \\
-0.02 \\
0.12 \\
0.33 \\
0.48 \\
0.01 \\
0.12 \\
0.22 \\
0.41 \\
-\end{array}$ & $\begin{array}{l}0 \\
-0.15^{b} \\
-0.07 \\
0.04 \\
0.38 \\
0.47 \\
-0.125 \\
-0.45^{c} \\
-0.16 \\
0.25 \\
-\end{array}$ \\
\hline
\end{tabular}
"butylmagnesium bromide" in diethyl ether at $25^{\circ} \mathrm{C}\left(c^{\circ}{ }_{\mathrm{ArOCN}}=0.010 \mathrm{M}\right.$ and $c^{\circ}$ "c $\mathrm{C}_{\mathrm{H}} \mathrm{MgBr}$ " $\left.=0.100 \mathrm{M}\right)$.

${ }^{a} \sigma^{0}$-values from Ref. 6 unless another means is indicated. ${ }^{b}$ This value is from Ref. 7. $^{c}$ This value is from Ref. 8. 


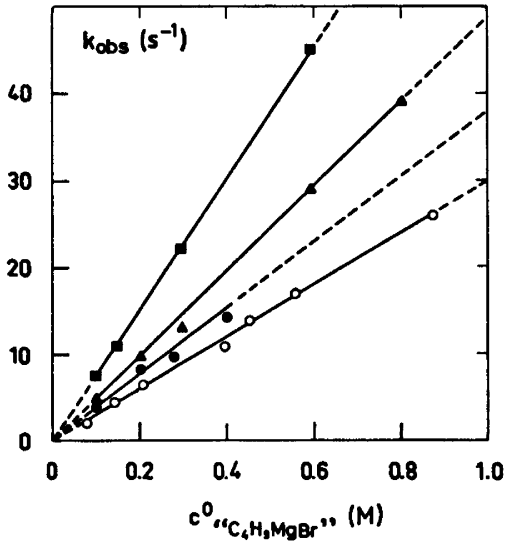

Fig. 6. Plot of pseudo first order rate constants versus the initial concentrations of the Grignard reagent for the reactions of $p$-substituted phenyl cyanates with excess "butylmagnesium bromide" in diethyl ether at $25^{\circ} \mathrm{C}\left(c^{0}{ }_{p-\mathrm{XC}_{6} \mathrm{H}_{4} \mathrm{OCN}}=\right.$ $0.010 \quad \mathrm{M} ; \quad p-\mathrm{CH}_{3} \mathrm{C}_{6} \mathrm{H}_{4} \mathrm{OCN} \quad(\mathrm{O}) ; p-$ $\left(\mathrm{CH}_{3}\right)_{2} \mathrm{CHOC}_{6} \mathrm{H}_{4} \mathrm{OCN}(\mathrm{O}) ; p-\mathrm{CH}_{3} \mathrm{OC}_{6} \mathrm{H}_{4} \mathrm{OCN}$ ( $\left.\Delta) ; p-\mathrm{ClC}_{6} \mathrm{H}_{4} \mathrm{OCN}(\boldsymbol{\square})\right)$.

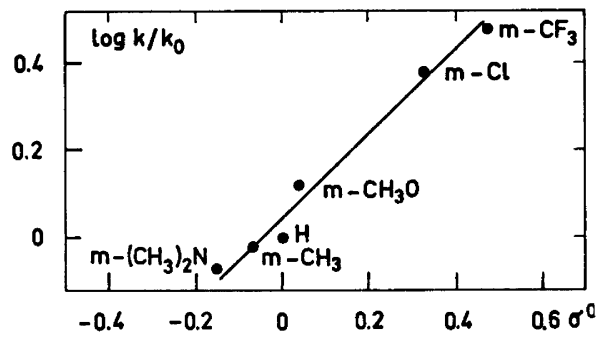

Fig. 7. Plot of $\log k / k_{0}$ versus $\sigma^{0}$ for the reaction between $m$-substituted phenyl cyanates and "butylmagnesium bromide" in diethyl ether at $25^{\circ} \mathrm{C}\left(c^{0}{ }_{m-\mathrm{XC}_{\odot} \mathrm{H}_{\iota} \mathrm{OCN}}=0.010 \mathrm{M}\right.$ and $c^{0}$ " $\mathrm{C}_{4} \mathrm{H}_{\bullet} \mathrm{MgBr}$ " $=0.100 \mathrm{M})$.

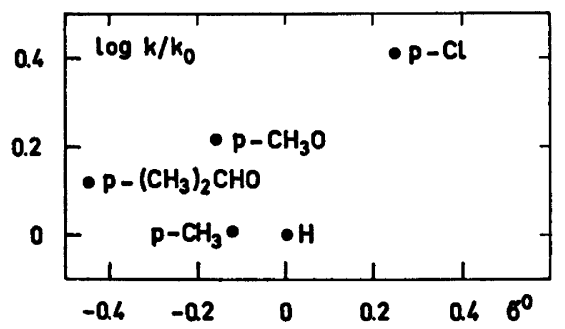

Fig. 8. Plot of $\log k / k_{0}$ versus $\sigma^{0}$ for the reaction between $p$-substituted phenyl cyanates and "butylmagnesium bromide" in diethyl ether at $25^{\circ} \mathrm{C}\left(c^{0}{ }_{p-\mathrm{XC}_{6} \mathrm{H}_{4} \mathrm{OCN}}=0.010 \mathrm{M}\right.$ and $c^{0}$ " $\mathrm{C}_{4} \mathrm{H} . \mathrm{MgBr}$ " $=0.100 \mathrm{M})$.

Acta Chem. Scand. B 28 (1974) No. 7
Kinetic measurements have been carried out on reactions between $m$ - and $p$-substituted phenyl cyanates and excess "butylmagnesium bromide". Pseudo first order plots were in all cases linear until $70 \%$ transformation of the substituted cyanates, and the pseudo first order rate constants obtained from these plots were linearly dependent on the initial concentration of "butylmagnesium bromide" (Figs. 5 and 6).

The logarithm of the pseudo first order rate constants for the reactions of $m$-substituted phenyl cyanates with "butylmagnesium bromide" could be linearly correlated with the Hammett sigma values (Table 5 and Fig. 7). The slope of the line is positive $(\varrho=+0.97)$. The logarithm of the pseudo first order rate constants found in reactions of $p$-substituted phenyl cyanates with "butylmagnesium bromide" could not be linearly correlated with the Hammett sigma values (Table 5 and Fig. 8). The rate constants are increased both when the substituent is electron-attracting (Cl) and when the substituent is electron-donating $\left(\mathrm{CH}_{3}\right.$, $\left(\mathrm{CH}_{3}\right)_{2} \mathrm{CHO}$ and $\left.\mathrm{CH}_{3} \mathrm{O}\right)$, and the points could not be connected by a smooth curve. It thus seems hazardous on this basis to draw any detailed mechanistic conclusions. However, the increased rate observed in reactions with $p$. substituted phenyl cyanates is in itself an indication of a change either in reaction mechanism or in the transition state.

The most reactive of the aromatic cyanates we have investigated is 2,6-dimethylphenyl cyanate (Table 5). The pseudo first order plots obtained in kinetic measurements with excess "butylmagnesium bromide" are linear up to $70 \%$ transformation of 2,6-dimethylphenyl cyanate, and the pseudo first order rate constant is linearly dependent on the initial concentration of "butylmagnesium bromide" (Fig. 9). The apparent steric acceleration may be due to restricted rotation of the cyanate group with resulting decrease of conjugation with the phenyl group. Thus the inductive effect of the phenyl group becomes more pronounced, causing a reaction rate acceleration in accord with the observed positive sign of the reaction constant.

Aromatic Grignard reagents were found to be much more reactive towards phenyl cyanate than "butylmagnesium bromide" and more 


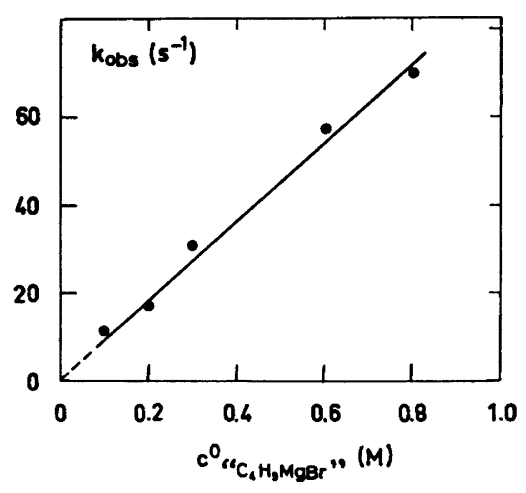

Fig. 9. Plot of pseudo first order rate constants versus the initial concentrations of the Grignard reagent for the reaction of 2,6-dimethylphenyl cyanate with "butylmagnesium bromide" in diethyl ether at $25^{\circ} \mathrm{C}\left(c_{2,6}^{0}-\left(\mathrm{CH}_{3}\right)_{2} \mathrm{C}_{6} \mathrm{H}_{3} \mathrm{OCN}=0.010\right.$ M).

reactive even than dibutylmagnesium (Table 6). When the aromatic Grignard reagent is substituted in the para-position an electrondonating substituent $\left(\mathrm{CH}_{3}\right)$ makes the Grignard reagent more reactive towards phenyl cyanate and an electron-attracting substituent (C1) reduces the reactivity of the Grignard reagent. From the $k_{\mathrm{obs}}$-values and the Hammett sigma values a reaction constant $(\varrho)$ of -0.8 can be calculated.

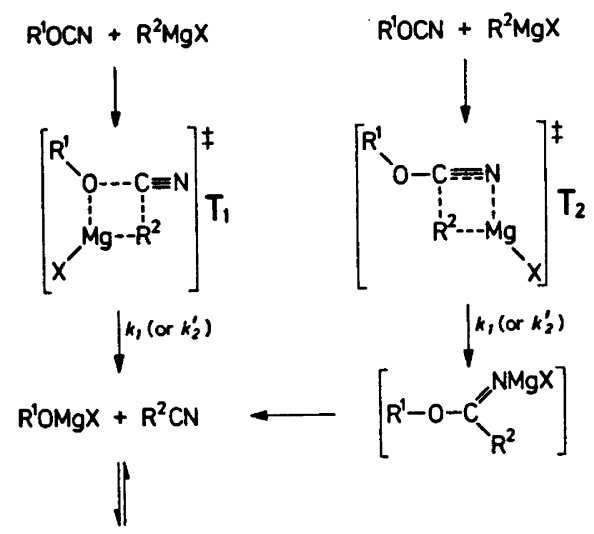

[R'OMgX, $\mathrm{R}^{2} \mathrm{CN}$ ]

$R^{2}=$ alkyl or aryl

$X=$ halogen, alkyl or aryl
Table 6. Pseudo first order rate constants for the reaction of $0.010 \mathrm{M}$ phenyl cyanate with different Grignard reagents ( $c^{0}$ " $\mathrm{RMgx}$ " $=0.100$ $\mathrm{M})$ and dibutylmagnesium $\left(c^{0}{ }_{\mathrm{R}_{2} \mathrm{Mg}}=0.100 \mathrm{M}\right)$ in diethyl ether at $25^{\circ} \mathrm{C}$.

\begin{tabular}{|c|c|}
\hline " $\mathrm{RMgX}$ " or $\mathrm{R}_{2} \mathrm{Mg}$ & $k_{\text {obs }}\left(\mathrm{s}^{-1}\right)$ \\
\hline $\begin{array}{l}\text { " } p-\mathrm{CH}_{3} \mathrm{C}_{6} \mathrm{H}_{4} \mathrm{MgBr} " \\
\text { " } \mathrm{C}_{6} \mathrm{H}_{5} \mathrm{MgBr}^{3} \text { " } \\
" ~ p-\mathrm{ClC}_{6} \mathrm{H}_{4} \mathrm{MgBr} " \\
\left(\mathrm{C}_{4} \mathrm{H}_{9}\right)_{2} \mathrm{Mg} \\
" \text { " } \mathrm{C}_{4} \mathrm{H}_{9} \mathrm{MgBr} " \\
\text { " } t-\mathrm{C}_{4} \mathrm{H}_{9} \mathrm{MgCl} "\end{array}$ & $\begin{array}{r}248 \\
192 \\
85 \\
65 \\
2.9 \\
<2.9\end{array}$ \\
\hline
\end{tabular}

A radical mechanism for the reaction between aryl cyanates and Grignard reagents can probably be excluded. First of all the formation of only a few products in high yields does not indicate the presence of free radicals. In reactions of Grignard reagents where free radicals are formed several products are observed, as for example in the case of the reaction of " $t$-butylmagnesium chloride" with benzo. phenones. In the reactions of benzophenone with different Grignard reagents " $t$-butylmagnesium chloride" also exhibited the highest measured reaction rate. ${ }^{10}$ In the present case " $t$-butylmagnesium chloride" on the contrary has the smallest reaction rate. Furthermore, despite a number of experiments using flow technique we have not observed radicals in ESR measurements.

As shown above the reaction order for the reaction between aryl cyanates and Grignard reagents is two, first order in both reactants. For $m$-substituted aryl cyanates $k_{\text {obs-values }}$ are linearly dependent on the initial concentration of the reagent in excess, signifying lack of complex formation prior to the rate-determining step. In the rate-determining step two alternative pathways have to be considered. 1. Attachment of magnesium directly to the oxygen atom synchronously with nitrile formation. 2. Attachment of magnesium to nitrogen followed by a further reaction, to give products (Scheme 1).

In case 1 the positive sign of the reaction constant, $\varrho_{\mathrm{ArOCN}}=+0.97$, is in agreement with development of a negative charge on oxygen, as will be the case if phenolate is formed. Similarly the negative sign of the reaction

\section{Scheme 1.}

Acta Chem. Scand. B 28 (1974) No. 7 
constant $\varrho_{\text {ArMgX }}=-0.80$ fulfills the electronic requirements for the formation of the bond between the nitrile group and the Grignard reagent. The size of the constants here observed will, however, normally be associated with a transition state of low polarity. Comparison with reaction constants for reactions of Grignard reagents where the mechanism is known has not been possible. The low polarity of the transition state seems to be evidence against reaction path 1 , but it is, however, hardly conclusive since a bond is formed to magnesium concurrently with breaking of the oxygencarbon bond. This reduces the polarity of the transition state since the bond between oxygen and magnesium has some covalent character $(27 \%),{ }^{11}$ but the extent of this effect is uncertain.

The second pathway implies formation of an imido ester salt, for which no evidence has been brought to light despite carefull scrutiny. ${ }^{1}$ Still this intermediate cannot be excluded on these grounds since it can be interpreted to mean that the rate constant for the decomposition of the imido ester salt is much bigger than the rate constant for the formation of the imido ester salt. Magnesium salts of simple imido esters are unknown in general, but a few examples of isolation of imido esters, where apparently the salts are intermediates, are reported when a strongly electron-attracting group is present in the molecule. Thus an imido ester can be obtained from the reaction between sodium malonodinitrile and phenyl cyanate, ${ }^{12}$ and the reaction of ethyl cyanate with hydrogen cyanide in pyridine yields the corresponding imido ester. ${ }^{13}$ The reaction of nitriles with an alcohol in the presence of alcoholate likewise yields imido esters. ${ }^{14-16}$ These observations may be considered as an indication of the intermediacy of an imido ester also in the case of the reaction with Grignard reagents. On first consideration this gains support from the fact that in the reaction between imido esters and Grignard reagents, which similarly leads to alcoholates and nitriles, imido esters cannot be regenerated after mixing of the reactants even when using the flow technique. ${ }^{17}$ Some caution, however, is necessary in the evaluation of this result, since it may well be that the abstraction of the proton from the imido ester by the Grignard reagent proceeds by a cyclic concerted reaction not leading to salt formation (III).

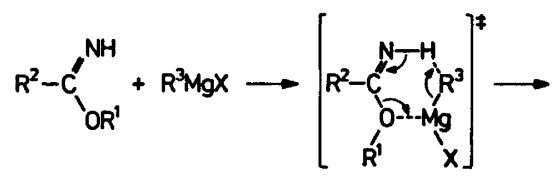

$$
R^{2} C N+R^{\prime} O M g X+R^{3} H
$$

It is also in the case of pathway 2 difficult to evaluate what is to be expected with regard to the reaction constant. The aryl group in the cyanate is removed to a greater distance from the reaction center, and the screening effect of the oxygen atom could explain the low value of the reaction constant.

No conclusive evidence can be produced for either of the two alternatives, and evidently these reactions need more attention.

\section{EXPERIMENTAL}

All Grignard reagents were prepared in diethyl ether distilled from lithium aluminum hydride directly into the glass apparatus. This solvent was used in all experiments. The magnesium used (monosublimed, Dow Chemical Corp.) was washed with anhydrous diethyl ether. Every precaution was taken against oxygen and moisture. The halides used in the preparations of the Grignard reagents were distilled or recrystallized and their purity checked gas-chromatographically. In preparations of Grignard reagents an excess of magnesium was always used. The molarity of the Grignard reagents was determined by titration with standard acid and the content of halogen by titration with standard silver nitrate. The content of halogen was never more than $4 \%$ higher than the content of Grignard reagent. The different concentrations were obtained by dilution of $c a .2 \mathrm{M}$ standard solutions.

The aryl cyanates were prepared from phenols and cyanogen chloride in the presence of triethylamine. ${ }^{18}$ The purity of the cyanates was checked by infrared and proton magnetic resonance spectroscopy and elemental analysis.

Dibutylmagnesium was prepared from "butylmagnesium chloride" and butyllithium. ${ }^{10}$

Magnesium bromide etherate was prepared from 1,2-dibromoethane. ${ }^{20}$

A detailed description of the apparatus used for the kinetic measurements is given in Ref. 2.

Acknowledgements. The authors are very grateful to Professor Martin Ettlinger for his interest in and valuable discussions of this work.

Acta Chem. Scand. B 28 (1974) No. 7 


\section{REFERENCES}

1. Holm, A. and Huge-Jensen, E. Acta Chem. Scand. B 28 (1974) 705.

2. a. Holm, T. Acta Chem. Scand. 21 (1967) 2753; b. Holm, A., Holm, T. and HugeJensen, E. Acta Chem. Scand. B 28 (1974) 781.

3. Walker, F. W. and Ashby, E. C. J. Amer. Chem. Soc. 91 (1969) 3845.

4. Schlenk, W. and Schlenk, W., Jr. Ber. Deut. Chem. Ges. 62 (1929) 920.

5. Holm, T. Acta Chem. Scand. 20 (1966) 2821.

6. Cohen, L. A. and Takahashi, S. J. Amer. Chem. Soc. 95 (1973) 443.

7. Leffler, J. E. and Grunwald, E. Rates and Equilibria of Organic Reactions, Wiley, New York and London 1963, p. 215.

8. Ref. 7, p. 173.

9. Holm, T. and Crossland, I. Acta Chem. Scand. 25 (1971) 59.

10. Holm, T. Acta Chem. Scand. 23 (1969) 579.

11. Pauling, L. The Nature of the Chemical Bond, 3rd Ed., Cornell University Press, Ithaca 1960, Chapter 3.

12. Grigat, E., Pütter, R. and Mühlbauer, E. Chem. Ber. 98 (1965) 3777.

13. Wentrup, C. Acta Chem. Scand. 29 (1966) 2128.

14. Schaefer, F. C. and Peters, G. A. J. Org. Chem. 26 (1961) 412.

15. Brown, H. C. and Wetzel, C. R. J. Org. Chem. 30 (1965) 3724.

16. Cramer, F., Powelzik, K. and Baldauf, H. J. Chem. Ber. 91 (1958) 1049.

17. Huge-Jensen, E. To be published.

18. Grigat, E. and Pütter, R. Chem. Ber. 97 (1964) 3012.

19. Kamienski, C. W. and Eastham, J. F. J. Organometal. Chem. 8 (1967) 542 .

20. Ashby, E. C. and Arnott, R. C. J. Organometal. Chem. 14 (1968) 1.

Received February 21, 1974. 